\title{
The prevalence of diagnosed $\alpha_{1}$-antitrypsin deficiency and its comorbidities: results from a large population-based database
}

\author{
Timm Greulich ${ }^{1}$, Christoph Nell ${ }^{1}$, David Hohmann², Marco Grebe ${ }^{3}$, \\ Sabina Janciauskiene ${ }^{4}$, Andreas Rembert Koczulla ${ }^{1}$ and Claus Franz Vogelmeier ${ }^{1}$ \\ Affiliations: ${ }^{1}$ Dept of Medicine, Pulmonary and Critical Care Medicine, University Medical Centre Giessen and \\ Marburg, Philipps-University, Member of the German Centre for Lung Research (DZL), Marburg, Germany. \\ ${ }^{2} \mathrm{HGC}$ GesundheitsConsult GmbH, Düsseldorf, Germany. ${ }^{3}$ Grifols Deutschland GmbH, Frankfurt, Germany. ${ }^{4}$ Dept \\ of Respiratory Medicine, Hannover Medical School, Biomedical Research in Endstage and Obstructive Lung \\ Disease Hannover (BREATH), Member of the German Center for Lung Research (DZL), Hannover, Germany.
}

Correspondence: Timm Greulich, Dept of Medicine, Pulmonary and Critical Care Medicine, University Medical Centre Giessen and Marburg, Philipps-University, 35043 Marburg, Germany.

E-mail: greulichamed.uni-marburg.de

@ERSpublications

AATD patients have higher healthcare utilisation relative to non-AATD COPD, emphysema and asthma patients http://ow.ly/pHHh303m025

Cite this article as: Greulich T, Nell C, Hohmann D, et al. The prevalence of diagnosed $\alpha_{1}$-antitrypsin deficiency and its comorbidities: results from a large population-based database. Eur Respir J 2017; 49: 1600154 [https://doi.org/10.1183/13993003.00154-2016].

ABSTRACT $\alpha_{1}$-Antitrypsin deficiency (AATD) is a genetically determined disorder that is associated with different clinical manifestations. We aimed to assess the prevalence of diagnosed AATD and its comorbidities using a large healthcare database.

In this retrospective longitudinal observational study, we analysed data from 4 million insurants. Using International Classification of Diseases revision 10 (ICD-10) codes, we assessed the prevalence, comorbidities and healthcare utilisation of AATD patients (E88.0 repeatedly coded) relative to non-AATD patients with chronic obstructive pulmonary disease (COPD), emphysema or asthma.

In our study population, we identified 673 AATD patients (590 aged $\geqslant 30$ years), corresponding to a prevalence of 23.73 per 100000 in all age groups and 29.36 per 100000 in those $\geqslant 30$ years. Based on the number of AATD cases detected in the sample size (673 out of 2836585$)$, we extrapolated that there were 19162 AATD cases in Germany during the years studied. AATD patients had a higher prevalence of arterial hypertension, chronic kidney disease and diabetes relative to non-AATD asthma or emphysema patients. When compared to non-AATD COPD patients, AATD patients had significantly more consultations and more frequent and longer hospitalisations.

Our data strengthen the assumption that AATD is associated with a variety of other diseases. Healthcare utilisation appears to be higher among AATD patients as compared to patients with non-AATD-related obstructive lung diseases.

This article has supplementary material available from erj.ersjournals.com

Received: June 212016 | Accepted after revision: Aug 172016

This study was supported by Grifols Deutschland GmbH (Frankfurt, Germany). Data adjustment and analysis were performed by the Health Risk Institute in coordination with Elsevier Health Analytics (both Berlin, Germany). The financial supporter had no influence on the analysis or the final presentation of the data. Funding information for this article has been deposited with the Open Funder Registry.

Conflict of interest: Disclosures can be found alongside this article at erj.ersjournals.com

Copyright OERS 2017 


\section{Introduction}

$\alpha_{1}$-Antitrypsin deficiency (AATD) is a genetically determined condition that can affect different organs, leading to various clinical manifestations, including pulmonary emphysema, liver cirrhosis, cytoplasmic anti-neutrophil cytoplasmic antibody (c-ANCA)-positive vasculitis and the inflammatory skin disease panniculitis [1]. The most common clinically relevant AATD alleles are $\mathrm{Pi}^{\star} \mathrm{Z}$ (Glu342Lys) and $\mathrm{Pi}^{\star} \mathrm{S}$ (Glu264Val). In the European population the frequency of homozygous AATD is estimated to be at $0.01-0.02 \%[2,3]$. However, owing to the lack of large-scale population-based studies, the exact prevalence in most European countries remains unknown.

The predominant disease manifestation is AATD-related emphysema, which is considered a specific phenotype of chronic obstructive pulmonary disease (COPD) [4]. Our understanding of general COPD has improved over the past decade. In this context, large epidemiological studies and clinical trials have helped us to understand the importance of comorbidities. Among the most frequent COPD-associated comorbidities are cardiovascular disease (CVD), osteoporosis and osteopenia, diabetes, cancer, depression/ anxiety, chronic kidney diseases (CKD), and anaemia [5-9]. In contrast, systematically gathered data on comorbidities of AATD are missing.

Our objective was to assess the prevalence of diagnosed AATD and its association with comorbidities using "real world" data from a large health insurance system in Europe.

\section{Methods \\ Study population}

We conducted a longitudinal cohort study using health insurance data from Germany. German statutory health insurance covers 69.9 million people $(87 \%$ of the total population, which is approximately 81 million people). Of those, 11.6 million are covered by a company health insurance fund [10]. Anonymous health claims data from a research sample of this cohort with 6.5 million insurants were obtained and adjusted for age and sex according to the distribution within the German population [10]. Validation of health risks associated with morbidity was performed according to annually published morbidity prevalence data as provided by the Federal Insurance Authority. This authority is responsible for the implementation of a risk structure compensation scheme [11, 12]. The methodology has been widely used before [13-15]. For our study, a representative 5\% sample of the general German population, consisting of approximately 4 million individuals, was randomly obtained for every available year between 2008 and 2013. Longitudinal data for these individuals were derived from a 2-year inclusion period in 2012 and 2013 and a retrospective 4-year observation period between 2008 and 2011. Individuals with missing insurance status in one of the relevant years, e.g. owing to a change of health insurance fund, were excluded. Finally, a set of 2836585 insurants was evaluated in this study (figure 1).

\section{Case definition}

A patient was defined as having AATD by the presence of an inpatient or outpatient International Classification of Diseases revision 10 (ICD-10) diagnosis code E88.0 in both 2012 and 2013 (repeatedly coded). It is important to note that ICD-10 code E88.0 does not differentiate between homozygous and heterozygous AATD patients and includes bisalbuminaemia. The AATD patient group was compared to groups of non-AATD patients who had COPD (ratio 1:10), emphysema (ratio 1:5) or asthma (ratio 1:10). Each of the three reference groups was demographically adjusted to the prevalent AATD patients using frequency matching for gender and age (5-year intervals).

A patient was defined as having COPD by the presence of an inpatient or outpatient ICD-10 diagnosis code J44 in 2012 and 2013. The emphysema and asthma patients were identified by inpatient or outpatient ICD-10 diagnosis codes J43 and J45, respectively. To exclude patients with overlapping diagnoses, we did not include patients if more than one of the diagnoses (J43, J44, J45) had been coded. Patients younger than 30 years were also excluded from analysis in all patient groups. To describe lung function in AATD-related and non-AATD-related COPD, we used data from ICD-10 subgroups ( $\mathrm{j} 44 . \mathrm{x} 0-\mathrm{j} 44 . \mathrm{x} 3$ ). ICD diagnostic codes that were used for the definitions of comorbidities can be found in supplementary table S1.

\section{Statistical analysis}

Data are presented as mean \pm SD or percentage values unless stated otherwise. To compare the frequencies of comorbidities for two patient groups (AATD versus others), the Chi-squared test was used. All probability values reported are two-sided, and a probability value of $\mathrm{p}<0.05$ was considered to indicate statistical significance.

The software packages GraphPad Prism Version 6.03 (GraphPad Software, La Jolla, CA, USA), SPSS Version 20 (SPSS Inc., Chicago, IL, USA) and SAS Version 9.3 (SAS Institute Inc., Cary, NC, USA) were used for all statistical analyses. 


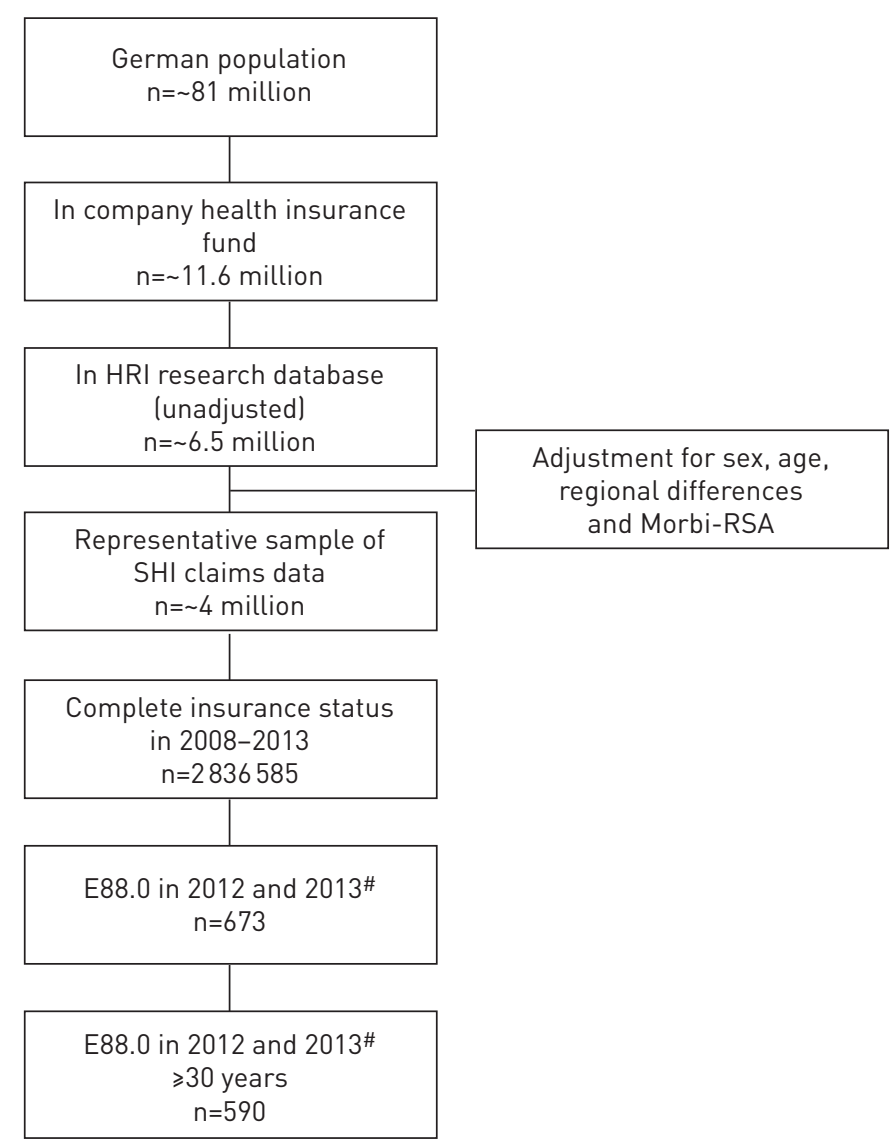

FIGURE 1 Flow chart demonstrating the restrictions used for the primary dataset in order to obtain the final dataset, used for further analyses. ${ }^{\sharp}$ : E88.0 had to be repeatedly coded lat least once in 2012 and at least once in 2013). HRI: Health Risk Institute; Morbi-RSA: Morbidity Risk Adjustment Scheme; SHI: statutory health insurance.

\section{Results}

Study population

After restricting the primary dataset to patients with a complete insurance status between 2008 and 2013, 2836585 patients remained in the analysis. The prevalent AATD group included 673 individuals (mean age $55.5 \pm 20.2$ years), of whom 590 had a minimum age of 30 years (figure 1 , table 1 ). We utilised this group for further analysis (51.51\% male, mean age 61.01 \pm 14.57 years, range $30-91$ years). The prevalence of AATD in our population (representative for the German population) was 23.73 per 100000 in all age groups and 29.36 per 100000 in those individuals aged $\geqslant 30$ years (table 1 ).

TABLE 1 Number of individuals in the study population, number of AATD cases (E88.0 repeatedly coded) and corresponding prevalence in certain age- and gender-matched groups

\begin{tabular}{|c|c|c|c|c|c|c|c|c|c|}
\hline \multirow[t]{2}{*}{ Age groups years } & \multicolumn{3}{|c|}{ Individuals in study population } & \multicolumn{3}{|c|}{ E88.0 cases (repeatedly coded) } & \multicolumn{3}{|c|}{ Prevalence per 100000} \\
\hline & Females & Males & All & Females & Males & All & Females & Males & All \\
\hline $0-29$ & 403070 & 423878 & 826948 & 30 & 53 & 83 & 7.44 & 12.50 & 10.04 \\
\hline $0-29$ & 403070 & 423878 & 826948 & 30 & 53 & 83 & 7.44 & 12.50 & 10.04 \\
\hline $30-44$ & 262129 & 267641 & 529771 & 37 & 49 & 86 & 14.12 & 18.31 & 16.23 \\
\hline $75+$ & 176988 & 121710 & 298698 & 74 & 45 & 119 & 41.81 & 36.97 & 39.84 \\
\hline All ages & 1435556 & 1401029 & 2836585 & 322 & 351 & 673 & 22.43 & 25.05 & 23.73 \\
\hline
\end{tabular}


Based on the number of AATD patients (repeatedly coded in 2012 and 2013) and on the German population data from the Federal Statistical Office (80767500 inhabitants in 2013), the estimated number of individuals with AATD, independent from the genotype or health status, was 19162 . Using the same ratio (2836585:80767500), the estimated number of patients with an additional diagnosis of any pulmonary disease was 8684 .

\section{Burden of comorbidity in AATD compared to age- and gender-matched populations of obstructive lung diseases}

To assess the relative impact of AATD on obstructive lung diseases, we compared the prevalence of comorbidities in AATD patients with the prevalence in matched reference population datasets of patients with COPD, emphysema and asthma. The burden of comorbidities in AATD and COPD was similar for the majority of comorbidities, although ischaemic heart disease and depression were more frequent within the COPD group and osteoporosis was more frequent in the AATD group. When compared to emphysema patients, AATD patients had a significantly higher prevalence of arterial hypertension, CKD and diabetes, but lung cancer was more prevalent in patients with emphysema than with AATD. Compared to asthma patients, AATD patients also more frequently had arterial hypertension, congestive heart failure, CKD, diabetes and osteoporosis (table 2).

According to previous reports, liver diseases, vasculitis and panniculitis are "typical" clinical manifestations of AATD [1]. Therefore, we investigated the prevalence of these diseases in COPD and AATD patient groups. Our results confirmed that liver diseases are more frequent among AATD patients than among COPD patients. However, the prevalence of vasculitis and panniculitis did not differ significantly between these groups (figure 2).

An analysis of patient subgroups with reported data regarding the severity of obstructive lung disease (ICD-10 subgroups) showed that patients with AATD-related COPD had more severe disease relative to those without AATD (figure 3).

\section{Utilisation of healthcare system resources}

Analysing the utilisation of the healthcare system, we found that AATD patients had more consultations than their age- and gender-matched reference groups with obstructive lung diseases (figure 4).

In concordance with these data, hospitalisation rates were higher for AATD patients than for their ageand gender-matched groups with obstructive lung diseases (figure 5).

\section{Discussion}

To our knowledge, this is the first report to provide the frequency of diagnosed AATD and the burden of AATD-related comorbidities based on a very large sample of health insurance data, which was retrieved for 2836585 individuals. When compared to non-AATD COPD patients, AATD patients had more comorbidities, more physician contacts and were more frequently hospitalised.

TABLE 2 Prevalence of comorbidities in prevalent AATD patients compared to age- and gender-matched reference populations of COPD (1:10), emphysema (1:5) and asthma (1:10).

$\begin{array}{ccccccc}\text { AATD } & \text { COPD } & \text { p-value (AATD } & \text { Emphysema } & \text { p-value } & \text { Asthma } & \text { p-value (AATD } \\ \text { (prevalent) } & \text { (matched) } & \text { versus COPD) } & \text { (matched) } & \begin{array}{c}\text { (AATD versus } \\ \text { (matched) }\end{array} & \text { versus asthma) }\end{array}$

\begin{tabular}{|c|c|c|c|c|c|c|c|}
\hline Subjects n & 590 & 5900 & & 1770 & & 5900 & \\
\hline Age years & $61.01 \pm 14.57$ & $61.1 \pm 14.55$ & 1.000 & $61.13 \pm 14.53$ & 1.000 & $61.0 \pm 14.57$ & 1.000 \\
\hline Male/female $n$ & $298 / 292$ & $2980 / 2920$ & 1.000 & $894 / 876$ & 1.000 & $2980 / 2920$ & 1.000 \\
\hline Arterial HTN & 63.39 & 65.47 & 0.174 & 58.14 & 0.014 & 59.47 & 0.035 \\
\hline Congestive heart failure & 22.03 & 23.86 & 0.172 & 20.90 & 0.301 & 18.39 & 0.035 \\
\hline Ischaemic heart disease & 20.85 & 24.98 & 0.030 & 23.73 & 0.158 & 19.15 & 0.325 \\
\hline Chronic kidney disease & 12.54 & 10.22 & 0.053 & 9.49 & 0.026 & 8.05 & $<0.001$ \\
\hline Depression & 31.36 & 35.14 & 0.036 & 33.79 & 0.150 & 31.24 & 0.507 \\
\hline Diabetes & 27.29 & 26.41 & 0.357 & 21.13 & 0.002 & 21.54 & 0.001 \\
\hline Osteoporosis & 16.27 & 13.12 & 0.032 & 17.23 & 0.591 & 12.8 & 0.017 \\
\hline GORD & 23.1 & 24.4 & 0.481 & 24.3 & 0.578 & 23.6 & 0.799 \\
\hline Lung cancer & 2.03 & 2.32 & 0.395 & 3.79 & 0.024 & 1.25 & 0.082 \\
\hline
\end{tabular}

Data are presented as percentage values, unless otherwise stated. All p-values are calculated with the Chi-squared test for two groups. AATD: $\alpha_{1}$-antitrypsin deficiency; COPD: chronic obstructive pulmonary disease; HTN: hypertension; GORD: gastro-oesophageal reflux disease. 


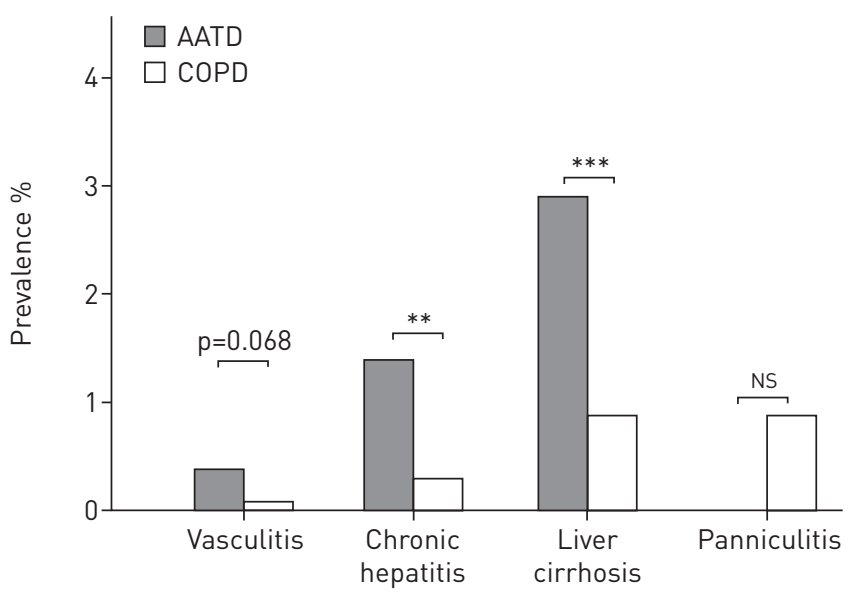

FIGURE 2 Prevalence of comorbidities in $\alpha_{1}$-antitrypsin deficiency (AATD) patients compared to age- and gender-matched chronic obstructive pulmonary disease (COPD) patients. Data are presented as percentage values. All $p$-values are calculated with the Chi-squared test for two groups. NS: not significant. ${ }^{* *}: p<0.01$; $* * *: p<0.001$.

In order to sharpen the ICD-10 definition of AATD, we used the restriction "repeatedly coded within two years". The idea behind this approach was that any misclassification would be corrected within 2 years. The ICD-10 code E88.0 also includes bisalbuminaemia. This rarely encountered inherited or acquired serum protein anomaly is characterised by the condition of having two types of serum albumin that differ in mobility during electrophoresis, resulting in a bicuspid electrophoretic pattern in the albumin fraction detected on serum electrophoresis [16]. Because the condition is very rare and does not have clinical implications [17], we assumed that E88.0 is reflecting AATD rather than bisalbuminaemia. This assumption is further supported by the analyses presented in figures 2 and 3, which confirm earlier reports about comorbidities and lung function in AATD that would not be true for bisalbuminaemia.

Based on the ICD-10 codes, which combine data for homozygous and heterozygous AATD patients, the prevalence of AATD in our population (representative of the German population) was 23.73 per 100000 in all age groups and 29.36 per 100000 in those individuals aged $\geqslant 30$ years. Because we had adjusted the health insurance database population for age, gender, regional differences and morbidity to match the total population in Germany, we were able to estimate the number of AATD patients in Germany. We estimated the number of diagnosed AATD patients in Germany to be 19162, of whom an estimated 8684 patients would have had an additional pulmonary diagnosis. The prevalence of COPD and emphysema in AATD was $32 \%$ and $21 \%$, respectively. The prevalence of diagnosed AATD increased with age (table 1). The data confirm reports that the majority of patients are diagnosed at the age of 45 or over, although symptoms

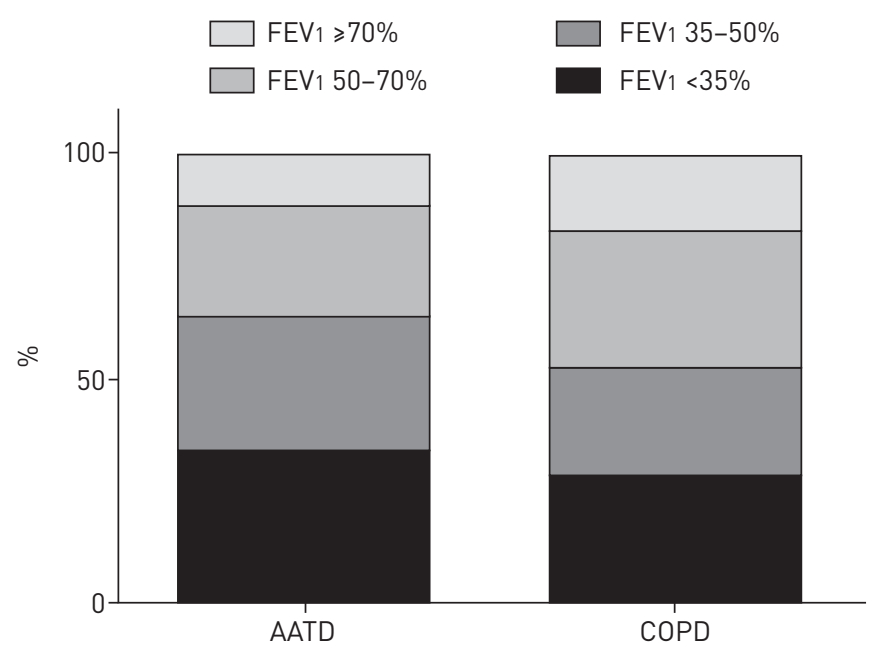

FIGURE 3 Lung function of $\alpha_{1}$-antitrypsin deficiency (AATD) patients ( $n=183$ ) compared to chronic obstructive pulmonary disease (COPD) patients ( $n=3454)$. $F E V 1$ : forced expiratory volume in $1 \mathrm{~s}$. 


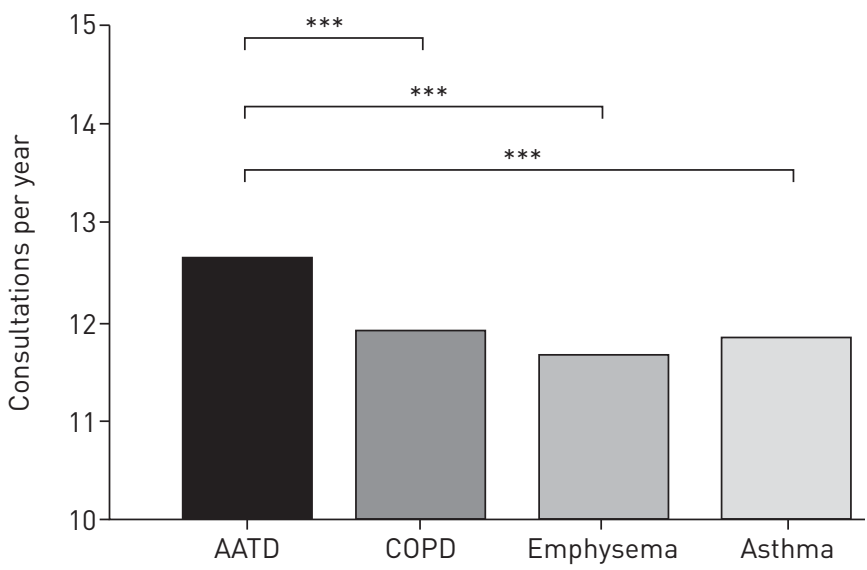

FIGURE 4 Number of ambulatory claims per patient and year for $\alpha_{1}$-antitrypsin deficiency (AATD) patients $(\mathrm{n}=590$ ) and age- and gender-matched chronic obstructive pulmonary disease (COPD) patients ( $n=5900$ ), emphysema patients $(n=1770)$ and asthma patients $(n=5900)$. The displayed $p$-values are comparisons versus AATD after an initial multiple group comparison (ANOVA with Dunn's correction). ${ }^{* * *}: p<0.001$.

usually start 5-10 years earlier [18-20]. Our estimate of the number of diagnosed AATD patients exceeds earlier estimates, i.e. 8003 homozygous individuals, given for Germany by BLANCO et al., but is smaller than the number of heterozygous individuals expected for Germany [21]. However, one cannot directly compare these numbers because the previous estimates were based on healthy controls only.

In addition to the "classic manifestations" of AATD (lung disease [22, 23], hepatic disease [24, 25], vasculitis $[26,27]$ and necrotising panniculitis $[28,29])$, co-occurrence of AATD with other diseases has been described, including rheumatoid arthritis [30], sinusitis associated with nasal polyps [31], inflammatory bowel diseases [32], peptic ulcer [33], arterial aneurysm [34], diabetes [35, 36] and more. The majority of these reports are based on small case series and thus may be subject to reporting bias. The lack of mechanistic explanation also prohibits certainty as to whether reported associations go beyond the coincidence of AATD and specific disease in the same person. In spite of that, our results support the assumption that AATD might be associated with clinical manifestations other than lung and liver disease. Comparing AATD patients to an age- and gender-matched random sample population (1:10), we found that all analysed comorbidities were more frequent in AATD (supplementary table S2). However, because screening for AATD is performed almost only in subjects with illness, these results should be viewed with caution.

In general, it is assumed that $\alpha_{1}$-antitrypsin (AAT) is responsible for protecting tissues against proteolytic damage by enzymes like neutrophil elastase and proteinase 3 [37]. Recent data support a notion that AAT

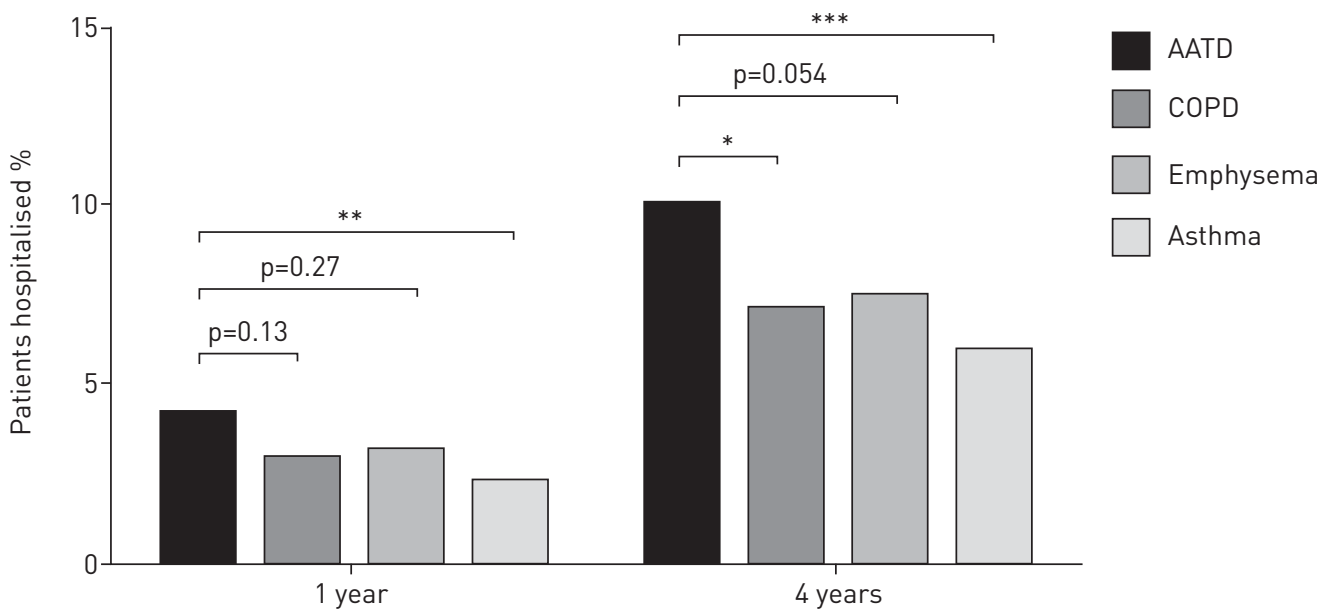

FIGURE 5 Analysis of hospitalisations of $\alpha_{1}$-antitrypsin deficiency (AATD) patients ( $n=590$ ) and age- and gender-matched chronic obstructive pulmonary disease (COPD) patients ( $n=5900)$, emphysema patients $(n=1770)$ and asthma patients $(n=5900)$. Displayed is the percentage of patients who were hospitalised at least once in a period of 1 year and 4 years, respectively. The four-group comparison (Chi-squared test) was significant ( $p=0.022)$; further comparisons were calculated with the Chi-squared test for two groups. ${ }^{*}: p<0.05$; ${ }^{* *}: p<0.01 ;{ }^{* * *}: p<0.001$. 
performs broader anti-inflammatory and/or immunoregulatory functions [38-43]. Moreover, AAT purified from human blood modulates and/or prevents tissue injury in experimental animal models of human diseases, including graft-versus-host-disease, inflammatory bowel disease, rheumatoid arthritis, acute liver failure, autoimmune diabetes, gouty arthritis and ischaemia-reperfusion injuries [44]. Because AAT is more than just an inhibitor of serine proteases, it is reasonable to believe that a pathophysiological link may exist between AATD and various comorbidities [45]. Interestingly, CKD was more frequent in the AATD group than in the emphysema group. One possible explanation for this may be that the polymerisation and dysfunction of $\mathrm{Z}$ AAT protein induces the formation of circulating immune complexes or may act as an antigen, impacting on CKD development [46, 47].

Our data highlight the more frequent outpatient consultations and hospitalisations among AATD patients compared to those with non-AAT COPD and emphysema. Moreover, AATD patients required longer hospitalisation (AATD: 10.28 days versus non-AATD COPD: 8.52 days). The cost of a hospital stay in Germany is approximately $€ 600$ per day [48]. These calculations allow us to conclude that the higher frequency and longer duration of hospitalisations for AATD patients have a substantially higher cost and resource burden on healthcare systems than those of non-AATD COPD patients. We think that further analyses regarding COPDand AATD-associated hospitalisations and their resulting costs in this database would be beneficial $[49,50]$.

The higher frequency of outpatient consultations, at least in part, may be explained by the application of specific augmentation therapy in a small subgroup of AATD patients; however, this does not apply to the hospitalisations. To the best of our knowledge, there are no studies directly comparing the hospitalisation rates of AATD patients to those of patients with other obstructive lung diseases, but exacerbations in AATD-related COPD seem to be more frequent than in non-AATD COPD. A few observational studies and randomised clinical trials reported that AATD patients receiving augmentation therapy have around two moderate or severe exacerbations per year [51,52]; a similar exacerbation rate has also been reported for AATD patients not on augmentation therapy [53]. According to COPD landmark trials, patients with comparable GOLD stages but without reported AATD experienced around one exacerbation per year $[54,55]$. This is of high clinical relevance given that hospitalised exacerbations are associated with decreased lung function [56], decreased quality of live [57] and an increased risk of death [58, 59]. Taken together, our findings support the assumption that healthcare utilisation of AATD patients is higher compared to that of non-AATD COPD and emphysema patients.

Our study has strengths and limitations. The most prominent strength of the study is that it for the first time uses a very large dataset to provide "real life" data on AATD. The critical limitation of our analysis is that it depends on the quality of ICD-10 diagnostic codes. The process of ICD coding is subject to numerous potential errors [60], and a validation study is lacking for AATD. In COPD, one validation study $(\mathrm{n}=442)$ was undertaken in Ontario, Canada, and demonstrated a sensitivity of $85.0 \%$ and a specificity of $78.4 \%$ [61]. A second study was performed in two Veterans Affairs medical centres in the USA ( $n=9573)$ and demonstrated a sensitivity of $76 \%$ and a specificity of $67 \%$ [62]. However, these COPD data may not necessarily reflect the situation in AATD. AATD testing rates are in general low and many subjects in the emphysema and COPD groups could also have had AATD. This may also provide a possible explanation for why panniculitis was shown to occur in the COPD group and not in the AATD group.

Secondly, the ICD-10 code does not differentiate between homozygous and heterozygous AATD. Furthermore, AAT serum level or individual data about disease severity (except ICD-10 code-derived) were not available, thus the E88.0 group could not be described in more clinical detail. On the other hand, the heterogeneity of our study population may even strengthen the importance of our findings regarding healthcare utilisation if applied to homozygous patients only, because any effect would have been "diluted" by heterozygous patients. A third limitation is that robust data on lung function, computed tomography data and smoking status are completely lacking in our analysis. Because these latter data were not available, we were not able to determine the number of patients that "could" or "should" receive augmentation therapy (according to current recommendations [63-65]) or to analyse the "impact" of augmentation therapy [66, 67].

We conclude that analyses of large healthcare databases provide important information, especially for orphan diseases. We show that AATD individuals have more physician contacts and are hospitalised more frequently than non-AATD COPD patients. Our findings highlight the benefits of large databases for studying the prevalence of orphan diseases and comorbidities, and encourage further investigations.

\section{References}

1 Silverman EK, Sandhaus RA. Clinical practice. Alpha1-antitrypsin deficiency. N Engl J Med 2009; 360: 2749-2757.

2 Hutchison DC. Alpha 1-antitrypsin deficiency in Europe: geographical distribution of Pi types S and Z. Respir Med 1998; 92: 367-377.

3 Sveger T. Liver disease in alphal-antitrypsin deficiency detected by screening of 200,000 infants. N Engl J Med 1976; 294: 1316-1321. 
4 Woodruff PG, Agusti A, Roche N, et al. Current concepts in targeting chronic obstructive pulmonary disease pharmacotherapy: making progress towards personalised management. Lancet 2015; 385: 1789-1798.

5 Mapel D. Insights into COPD comorbidities from the OLIN study and other large databases. COPD 2011; 8: 397-399.

6 Vanfleteren LE, Spruit MA, Groenen M, et al. Clusters of comorbidities based on validated objective measurements and systemic inflammation in patients with chronic obstructive pulmonary disease. Am J Respir Crit Care Med 2013; 187: 728-735.

7 Miller J, Edwards LD, Agusti A, et al. Comorbidity, systemic inflammation and outcomes in the ECLIPSE cohort. Respir Med 2013; 107: 1376-1384.

8 Feary JR, Rodrigues LC, Smith CJ, et al. Prevalence of major comorbidities in subjects with COPD and incidence of myocardial infarction and stroke: a comprehensive analysis using data from primary care. Thorax 2010; 65: 956-962.

9 Gershon AS, Mecredy GC, Guan J, et al. Quantifying comorbidity in individuals with COPD: a population study. Eur Respir J 2015; 45: 51-59.

10 Office GFS. Facts \& Figures - State \& Society - Federal Statistical Office (Destatis). 2015. www.destatis.de/EN/ FactsFigures/SocietyState/SocietyState.html Date last accessed: October 8, 2015.

11 Nuscheler R, Knaus T. Risk selection in the German public health insurance system. Health Econ 2005; 14: 1253-1271.

12 Buchner F, Goepffarth D, Wasem J. The new risk adjustment formula in Germany: implementation and first experiences. Health Policy 2013; 109: 253-262.

13 Andersohn F, Walker J. Characteristics and external validity of the German Health Risk Institute (HRI) Database. Pharmacoepidemiol Drug Saf 2016; 25: 106-109.

14 Ringshausen FC, de Roux A, Diel R, et al. Bronchiectasis in Germany: a population-based estimation of disease prevalence. Eur Respir J 2015; 46: 1805-1807.

15 Ringshausen FC, Wagner D, de Roux A, et al. Prevalence of nontuberculous mycobacterial pulmonary disease, Germany, 2009-2014. Emerging Infect Dis 2016; 22: 1102-1105.

16 Chhabra S, Bansal F, Saikia B, et al. Bisalbuminemia: a rarely encountered protein anomaly. J Lab Physicians 2013; 5: $145-146$.

17 Kragh-Hansen U, Minchiotti L, Galliano M, et al. Human serum albumin isoforms: genetic and molecular aspects and functional consequences. Biochim Biophys Acta 2013; 1830: 5405-5417.

18 Greulich T, Ottaviani S, Bals R, et al. Alpha1-antitrypsin deficiency - Diagnostic testing and disease awareness in Germany and Italy. Respir Med 2013; 107: 1400-1408.

19 Stoller JK, Sandhaus RA, Turino G, et al. Delay in diagnosis of alphal-antitrypsin deficiency: a continuing problem. Chest 2005; 128: 1989-1994.

20 Greulich T, Vogelmeier CF. Alpha-1-antitrypsin deficiency: increasing awareness and improving diagnosis. Ther Adv Respir Dis 2016; 10: 72-84.

21 Blanco I, de Serres FJ, Fernandez-Bustillo E, et al. Estimated numbers and prevalence of $\mathrm{PI}^{\star} \mathrm{S}$ and $\mathrm{PI} Z$ alleles of alpha1-antitrypsin deficiency in European countries. Eur Respir J 2006; 27: 77-84.

22 Laurell CB, Eriksson S. The electrophoretic alphal-globulin pattern of serum in alpha1-antitrypsin deficiency. 1963. COPD 2013; 10: Suppl. 1, 3-8.

23 Brantly ML, Paul LD, Miller BH, et al. Clinical features and history of the destructive lung disease associated with alpha-1-antitrypsin deficiency of adults with pulmonary symptoms. Am Rev Respir Dis 1988; 138: 327-336.

24 Sharp HL, Bridges RA, Krivit W, et al. Cirrhosis associated with alpha-1-antitrypsin deficiency: a previously unrecognized inherited disorder. J Lab Clin Med 1969; 73: 934-939.

25 Eriksson S. A 30-year perspective on alpha 1-antitrypsin deficiency. Chest 1996; 110: 6 Suppl., 237S-242S.

26 Audrain MA, Sesboue R, Baranger TA, et al. Analysis of anti-neutrophil cytoplasmic antibodies (ANCA): frequency and specificity in a sample of 191 homozygous (PiZZ) alphal-antitrypsin-deficient subjects. Nephrol Dial Transplant 2001; 16: 39-44.

27 Lyons PA, Rayner TF, Trivedi S, et al. Genetically distinct subsets within ANCA-associated vasculitis. $N$ Engl $J$ Med 2012; 367: 214-223.

28 Geraminejad P, Debloom JR, Walling HW, et al. Alpha-1-antitrypsin associated panniculitis: the MS variant. $J$ Am Acad Dermatol 2004; 51: 645-655.

29 Smith KC, Su WP, Pittelkow MR, et al. Clinical and pathologic correlations in 96 patients with panniculitis, including 15 patients with deficient levels of alpha 1-antitrypsin. J Am Acad Dermatol 1989; 21: 1192-1196.

30 Beckman G, Beckman L, Bjelle A, et al. Alpha-1-antitrypsin types and rheumatoid arthritis. Clin Genet 1984; 25: 496-499.

31 Maune S, Rath NF, Gorogh T, et al. [Genetic disposition to chronic polypoid sinusitis and alpha 1-proteinase inhibitor deficiency types]. HNO 1995; 43: 537-539.

32 Yang P, Tremaine WJ, Meyer RL, et al. Alphal-antitrypsin deficiency and inflammatory bowel diseases. Mayo Clin Proc 2000; 75: 450-455.

33 Elzouki AN, Toth E, Floren $\mathrm{CH}$, et al. Alpha1-antitrypsin deficiency may be a risk factor for duodenal ulcer in patients with Helicobacter pylori infection. Scand J Gastroenterol 2000; 35: 32-35.

34 Schardey HM, Hernandez-Richter T, Klueppelberg U, et al. Alleles of the alpha-1-antitrypsin phenotype in patients with aortic aneurysms. J Cardiovasc Surg (Torino) 1998; 39: 535-539.

35 Koulmanda M, Bhasin M, Hoffman L, et al. Curative and beta cell regenerative effects of alpha1-antitrypsin treatment in autoimmune diabetic NOD mice. Proc Natl Acad Sci U S A 2008; 105: 16242-16247.

36 Gottlieb PA, Alkanani AK, Michels AW, et al. alpha1-Antitrypsin therapy downregulates toll-like receptor-induced IL-1beta responses in monocytes and myeloid dendritic cells and may improve islet function in recently diagnosed patients with type 1 diabetes. J Clin Endocrinol Metab 2014; 99: E1418-E1426.

37 Gadek JE, Fells GA, Zimmerman RL, et al. Antielastases of the human alveolar structures. Implications for the protease-antiprotease theory of emphysema. J Clin Invest 1981; 68: 889-898.

38 Arora PK, Miller HC, Aronson LD. alpha1-Antitrypsin is an effector of immunological stasis. Nature 1978; 274: 589-590.

39 Dabbagh K, Laurent GJ, Shock A, et al. Alpha-1-antitrypsin stimulates fibroblast proliferation and procollagen production and activates classical MAP kinase signalling pathways. J Cell Physiol 2001; 186: 73-81. 
40 Bucurenci N, Blake DR, Chidwick K, et al. Inhibition of neutrophil superoxide production by human plasma alpha 1-antitrypsin. FEBS Lett 1992; 300: 21-24.

41 Tilg H, Vannier E, Vachino G, et al. Antiinflammatory properties of hepatic acute phase proteins: preferential induction of interleukin 1 (IL-1) receptor antagonist over IL-1 beta synthesis by human peripheral blood mononuclear cells. J Exp Med 1993; 178: 1629-1636.

42 Churg A, Dai J, Zay K, et al. Alpha-1-antitrypsin and a broad spectrum metalloprotease inhibitor, RS113456, have similar acute anti-inflammatory effects. Lab Invest 2001; 81: 1119-1131.

43 Churg A, Wang RD, Xie C, et al. alpha-1-Antitrypsin ameliorates cigarette smoke-induced emphysema in the mouse. Am J Respir Crit Care Med 2003; 168: 199-207.

44 Jonigk D, Al-Omari M, Maegel L, et al. Anti-inflammatory and immunomodulatory properties of alpha1-antitrypsin without inhibition of elastase. Proc Natl Acad Sci U S A 2013; 110: 15007-15012.

45 Janciauskiene SM, Bals R, Koczulla R, et al. The discovery of alpha1-antitrypsin and its role in health and disease. Respir Med 2011; 105: 1129-1139.

46 Morse JO. Alpha1-antitrypsin deficiency (second of two parts). N Engl J Med 1978; 299: 1099-1105.

47 Morse JO. Alpha1-antitrypsin deficiency (first of two parts). N Engl J Med 1978; 299: 1045-1048.

48 Bock JO, Brettschneider C, Seidl $\mathrm{H}$, et al. Ermittlung standardisierter Bewertungssätze aus gesellschaftlicher Perspektive für die gesundheitsökonomische Evaluation [Calculation of standardised unit costs from a societal perspective for health economic evaluation]. Gesundheitswesen 2015; 77: 53-61.

49 Wacker ME, Jorres RA, Karch A, et al. Assessing health-related quality of life in COPD: comparing generic and disease-specific instruments with focus on comorbidities. BMC Pulm Med 2016; 16: 70.

50 Wacker ME, Jorres RA, Schulz H, et al. Direct and indirect costs of COPD and its comorbidities: results from the German COSYCONET study. Respir Med 2016; 111: 39-46.

51 Campos MA, Alazemi S, Zhang G, et al. Exacerbations in subjects with alpha-1 antitrypsin deficiency receiving augmentation therapy. Respir Med 2009; 103: 1532-1539.

52 Dirksen A, Piitulainen E, Parr DG, et al. Exploring the role of CT densitometry: a randomised study of augmentation therapy in alphal-antitrypsin deficiency. Eur Respir J 2009; 33: 1345-1353.

53 Vijayasaratha K, Stockley RA. Reported and unreported exacerbations of COPD: analysis by diary cards. Chest 2008; 133: 34-41.

54 Calverley PM, Anderson JA, Celli B, et al. Salmeterol and fluticasone propionate and survival in chronic obstructive pulmonary disease. N Engl J Med 2007; 356: 775-789.

55 Decramer M, Celli B, Kesten S, et al. Effect of tiotropium on outcomes in patients with moderate chronic obstructive pulmonary disease (UPLIFT): a prespecified subgroup analysis of a randomised controlled trial. Lancet 2009; 374: 1171-1178.

56 Donaldson GC, Seemungal TA, Bhowmik A, et al. Relationship between exacerbation frequency and lung function decline in chronic obstructive pulmonary disease. Thorax 2002; 57: 847-852.

57 Bourbeau J, Ford G, Zackon H, et al. Impact on patients' health status following early identification of a COPD exacerbation. Eur Respir J 2007; 30: 907-913.

58 Johannesdottir SA, Christiansen CF, Johansen MB, et al. Hospitalization with acute exacerbation of chronic obstructive pulmonary disease and associated health resource utilization: a population-based Danish cohort study. J Med Econ 2013; 16: 897-906.

59 Soler-Cataluna JJ, Martinez-Garcia MA, Roman Sanchez P, et al. Severe acute exacerbations and mortality in patients with chronic obstructive pulmonary disease. Thorax 2005; 60: 925-931.

60 O’Malley KJ, Cook KF, Price MD, et al. Measuring diagnoses: ICD code accuracy. Health Serv Res 2005; 40 (5 Pt 2): $1620-1639$.

61 Gershon AS, Wang C, Guan J, et al. Identifying individuals with physician diagnosed COPD in health administrative databases. COPD 2009; 6: 388-394.

62 Cooke CR, Joo MJ, Anderson SM, et al. The validity of using ICD-9 codes and pharmacy records to identify patients with chronic obstructive pulmonary disease. BMC Health Serv Res 2011; 11: 37.

63 ATS/ERS. American Thoracic Society/European Respiratory Society statement: standards for the diagnosis and management of individuals with alpha-1 antitrypsin deficiency. Am J Respir Crit Care Med 2003; 168: 818-900.

64 Vidal R, Blanco I, Casas F, et al. Diagnóstico y tratamiento del déficit de alfa-1-antitripsina [Guidelines for the diagnosis and management of alpha-1 antitrypsin deficiency]. Arch Bronconeumol 2006; 42: 645-659.

65 Marciniuk DD, Hernandez P, Balter M, et al. Alpha-1 antitrypsin deficiency targeted testing and augmentation therapy: a Canadian Thoracic Society clinical practice guideline. Can Respir J 2012; 19: 109-116.

66 Chapman KR, Burdon JG, Piitulainen E, et al. Intravenous augmentation treatment and lung density in severe alpha1 antitrypsin deficiency (RAPID): a randomised, double-blind, placebo-controlled trial. Lancet 2015; 386: 360-368.

67 Stockley RA, Parr DG, Piitulainen E, et al. Therapeutic efficacy of alpha-1 antitrypsin augmentation therapy on the loss of lung tissue: an integrated analysis of 2 randomised clinical trials using computed tomography densitometry. Respir Res 2010; 11: 136. 